\title{
ACOMPANHAMENTO REOLÓGICO E MORFOLÓGICO DE CALDOS DE CULTIVOS DE E. coli RECOMBINANTE
}

\author{
G. G. SILVA ${ }^{1}$, J. H. BONOMO ${ }^{1}$, M. M. JESUS ${ }^{1}$, C. B. BORGES ${ }^{1}$, G. CAMPANI ${ }^{1}$, J. V. L. \\ ANDRADE ${ }^{1}$, V. M. GONÇALVES ${ }^{2}$, A. C. BADINO ${ }^{1}$, A. J. SILVA ${ }^{1}$, T. C. ZANGIROLAMI ${ }^{1}$ \\ ${ }^{1}$ Universidade Federal de São Carlos, Departamento de Engenharia Química \\ 2 Instituto Butantan, Centro de Biotecnologia \\ E-mail para contato: gabisfunny@ hotmail.com
}

\begin{abstract}
RESUMO - A bactéria E. coli é muito empregada para obtenção de proteínas heterólogas utilizadas na produção de fármacos e preparados enzimáticos. Porém, o estresse gerado pelas estratégias de crescimento e de expressão da proteína acarreta mudanças morfológicas no microrganismo, além de afetar a reologia do caldo de cultivo. Essas alterações e seus reflexos na síntese da proteína ainda não foram plenamente estabelecidos. Neste trabalho, avaliou-se a morfologia celular e a reologia dos caldos durante a produção de fragmento de proteína de superfície $S$. pneumoniae em E. coli. Os experimentos foram realizado em biorreator tipo tanque agitado, utilizando meio definido e IPTG ou lactose como indutores. Empregou-se o modelo de Herschel-Bulkley para descrever a reologia durante o processo de produção, observando-se uma mudança significativa do comportamento reológico do caldo. Constatou-se ainda que a razão entre a concentração celular (em massa seca) e a densidade ótica aumenta ao longo da fase de indução, devido provavelmente ao acúmulo de proteína intracelular. Imagens obtidas por microscopia ótica foram empregadas para caracterização morfológica, indicando o aparecimento de estruturas alongadas durante o cultivo conduzido sob indução por lactose. Os resultados contribuem para ampliar a compreensão do processo de produção de proteínas heterólogas por $\mathrm{r} E$. coli.
\end{abstract}

\section{INTRODUÇÃO}

Com os avanços e a popularização das técnicas de Biologia Molecular, microrganismos passaram a ser utilizados para a produção de uma grande diversidade de proteínas recombinantes, (Sargo, 2011). Dentre esses microrganismos, a bactéria Escherichia coli é apontada como uma das principais opções por apresentar diversas vantagens, que envolvem sua genética, sua estrutura e seu rápido crescimento (Nelson e Cox, 2006).

São relatadas na literatura várias estratégias para se alcançar altas concentrações de biomassa em cultivos de rE. coli (Horta, 2011) e otimizar a produção da proteína de interesse, porém a demanda metabólica imposta por essas estratégias pode afetar a bactéria de diversas formas. Nos cultivos de alta densidade celular, as células são submetidas a um regime de crescimento acelerado, o qual gera condições de estresse relacionadas à falta de nutrientes e oxigênio, e ao acúmulo de metabólitos inibidores. A exposição às condições estressantes pode levar a alterações no metabolismo assim como nas características fisiológicas e morfológicas, 
como já constatado em cultivos de alta densidade celular, nos quais células com formato esférico foram observadas (Koolaee et al., 2006). A exposição das bactérias aos agentes indutores e o estresse relacionado à produção da proteína recombinante durante a fase de indução também pode afetar a morfologia celular. A superexpressão da proteína heteróloga pode acarretar no bloqueio da produção de proteínas necessárias para a fase final da divisão celular, gerando assim indivíduos com característica filamentosa, que não conseguiram completar a clivagem celular (Lee, 1994, Lee et al., 1994).

As mudanças na concentração celular e as características morfológicas e fisiológicas das células afetam também a reologia do caldo, dificultando a transferência de massa e aumentando o consumo de energia no reator. Além disso, por estar ligada à morfologia celular, a reologia pode refletir o estado metabólico da mesma. Bactérias de caráter não filamentoso, como o caso da $E$. coli não apresentam grandes variações no comportamento reológico devido a não formação de aglomerados celulares do tipo micelar. Manon et al. (2009) monitoraram a reologia de um cultivo de E. coli, sem a expressão de proteínas recombinantes, em biorreator, entre as concentrações de $40 \mathrm{~g}$ de massa seca celular/L até $110 \mathrm{~g}$ de massa seca celular/L e verificaram que o comportamento reológico da suspensão celular permaneceu newtoniano. Porém, Silva et al. (2013) observaram mudanças no comportamento reológico de caldos de cultivo de $r E$. coli obtidos em diferentes condições de cultivo e indução, os quais apresentaram características de fluidos newtoniano, binghamiano e de Herschel-Bulkley.

Desta forma, esse trabalho teve como objetivo avaliar as características do cultivo, a reologia do caldo e a morfologia celular em culturas de E. coli para a produção de fragmento de proteína da superfície de $S$. pneumoniae PspA.

\section{MATERIAIS E MÉTODOS}

\subsection{Microrganismo e Meio de Cultura}

O microrganismo utilizado nos cultivos foi o bacilo gram-negativo Escherichia coli BL21(DE3) pET37b+/pspA4Pro, geneticamente modificado, expressando o fragmento da proteína PspA do clado 4 (PspA4Pro). Esta construção foi obtida no Laboratório de Biologia Molecular do Instituto Butantan e gentilmente cedida pela Dra. Eliane N. Miyaji. A PspA (proteína de superfície de pneumococo A) é uma candidata potencial para a produção de uma nova vacina contra o Streptococcus pneumoniae, pois está presente em todos os pneumococos isolados de material clínico. O plasmídeo pET37b+ contém o promotor T7 (induzido por IPTG ou lactose) e gene de resistência à canamicina. Em todas as etapas, foi utilizado meio de cultivo definido adaptado por Sargo (2011), contendo glicerol $(60 \mathrm{~g} / \mathrm{L})$ como fonte de carbono; $\left(\mathrm{NH}_{4}\right)_{2} \mathrm{HPO}_{4}(5,3 \mathrm{~g} / \mathrm{L})$ como fonte de nitrogênio; tiamina (45 mg/L), canamicina $(100 \mathrm{mg} / \mathrm{L})$, propilenoglicol $30 \% \mathrm{v} / \mathrm{v}(1 \mathrm{~mL} / \mathrm{L})$ e sais diversos. Todos os componentes foram previamente esterilizados por autoclavagem ou filtração em membrana de $0,2 \mu \mathrm{m}$.

\subsection{Métodos Analíticos}

O crescimento celular foi avaliado através de leitura de absorbância em espectrofotômetro a $600 \mathrm{~nm}\left(\mathrm{DO}_{600 \mathrm{~nm}}\right)$ e por meio da medida de massa seca $-\mathrm{C}_{\mathrm{x}}(\mathrm{gMS} / \mathrm{L})$. $\mathrm{O}$ número de células viáveis foi avaliado por contagem de unidades formadoras de colônia (UFC) presentes em meio sólido LB-ágar com antibiótico. Concentrações de glicerol, lactose 
e metabólitos (ácidos acético, lático e fórmico) foram determinadas por HPLC (sistema Waters Co; bombas HPLC 510, injetor W717, refratômetro W410 e leitor de UV PDA W996) utilizando a coluna Aminex HPX-87H (Bio-Rad) como fase estacionária e uma solução de $\mathrm{H}_{2} \mathrm{SO}_{4} 5 \mathrm{mM}$ como fase móvel, a uma vazão de $0,6 \mathrm{~L} / \mathrm{min}$ a $50^{\circ} \mathrm{C}$. A estabilidade do plasmídeo foi estimada por plaqueamento em meio sólido LB-ágar com e sem antibiótico (100 mg/L de canamicina) (Campani, 2014). A produção de proteína foi quantificada por SDS-PAGE e densitometria de banda (Campani, 2014). A partir de cada valor estimado para a concentração de PspA solúvel $\left(\mathrm{C}_{\mathrm{PspA}}\right)$, foi possível calcular a produção específica $-\mathrm{Y}_{\mathrm{PspA} / \mathrm{X}}$ em mgPspA/gMS.

O comportamento reológico do caldo foi avaliado utilizando reômetro de cilindros concêntricos (Brookfield®, modelo DC-III+). Após a coleta dos dados, a velocidade de cisalhamento $(\dot{\gamma})$ e tensão de cisalhamento $(\tau)$ foram empregados para o ajuste do modelo proposto por Herschel e Bulkley (Bennett e Myers, 1978), apresentado na Eq. 1, por regressão não linear, obtendo-se assim os valores dos parâmetros tensão de cisalhamento inicial $\left(\tau_{0}\right)$, índice de escoamento (n) e índice de consistência (k) para cada amostra. Este modelo pode ser simplificado para descrever os fluidos newtonianos $\left(n=1\right.$ e $\left.\tau_{0}=0\right)$ e binghamianos $(n=1)$.

$$
\tau=\tau_{0}+k \cdot \dot{\gamma}^{n}
$$

O acompanhamento da morfologia celular em microscópio ótico (Olympus ${ }^{\circledR}$, modelo BX50) foi realizado utilizando amostras do caldo retiradas no decorrer do cultivo e tratadas pelo método de Gram (Kyle et al., 2012). As imagens das lâminas bacteriológicas foram obtidas sob uma ampliação de 400 vezes através de sistema acoplado de aquisição digital de imagens. As imagens obtidas foram tratadas e binarizadas por um software de processamento de imagens (ImageJ) e estimativas de comprimento e largura das células presentes nas imagens foram obtidas através de rotina desenvolvida em MATLAB ${ }^{\circledR}$ (Andrade et al., 2013).

\subsection{Procedimento Experimental}

Para a realização dos cultivos, uma suspensão de células de $E$. coli BL21(DE3)pET37b+/PspA4Pro estocadas a $-80{ }^{\circ} \mathrm{C}$ com $10 \% \mathrm{v} / \mathrm{v}$ de glicerol foi inicialmente estriada em placa de Petri com LB-ágar e $100 \mathrm{mg} / \mathrm{L}$ de canamicina. Em seguida, a placa foi incubada por $24 \mathrm{~h}$ a $37^{\circ} \mathrm{C}$, sendo, então, transferida uma colônia para erlenmeyer estéril de $500 \mathrm{~mL}$ contendo $30 \mathrm{~mL}$ de meio de cultura para preparo do pré-inóculo. Este foi incubado em câmara rotativa a $270 \mathrm{rpm}$ e $37^{\circ} \mathrm{C}$ até $\mathrm{DO}_{600 \mathrm{~nm}}$ próxima de 2,5 . O inóculo foi preparado transferindo-se $5 \mathrm{~mL}$ do pré-inóculo para cada um dos três erlenmeyers estéreis de $500 \mathrm{~mL}$ contendo $100 \mathrm{~mL}$ de meio de cultura. A suspensão foi incubada a $270 \mathrm{rpm}$ e $37^{\circ} \mathrm{C}$ até uma $\mathrm{DO}_{600 \mathrm{~nm}}$ próxima de 2,5 , quando foi transferido todo o volume do inóculo $(0,3 \mathrm{~L})$ para o biorreator, dando início ao cultivo.

Os ensaios foram conduzidos em biorreator convencional de $5 \mathrm{~L}$ (volume nominal) construído no DEQ/UFSCar, dotado de um sistema de monitoramento e controle baseado no software HCDC SUPERSYS ${ }^{\circledR}$ desenvolvido por Horta (2011). As condições de cultivo empregadas foram: temperatura de $37^{\circ} \mathrm{C}$, $\mathrm{pH}$ de 6,3 (elevado progressivamente até 6,7 quando a DO atingiu 15) controlado através da adição de $\mathrm{NH}_{4} \mathrm{OH}$ ou $\mathrm{HCl}$ e concentração de oxigênio dissolvido mantido em $30 \%$ da saturação por meio da manipulação automática da velocidade de agitação e das vazões de ar e oxigênio puro (HORTA, 2011). A fase de produção da 
proteína foi iniciada por meio da aplicação de pulsos de lactose $(30 \mathrm{~g} / \mathrm{L})$ ou IPTG $(1 \mathrm{mM} / \mathrm{L})$ assim que a DO atingiu 25. Durante o cultivo induzido por IPTG, um pulso de glicerol foi adicionado ao atingir DO de 53,7 enquanto durante o cultivo induzido por lactose, um pulso de glicerol e lactose foi adicionado ao atingir Cx de 32,5 gMS/L. A suplementação com glicerol ou glicerol+lactose é necessária para evitar o esgotamento da fonte de carbono ou do indutor durante o período de indução. Amostras foram retiradas ao longo dos experimentos para a determinação de densidade ótica, estabilidade do plasmídeo, reologia, morfologia, concentração de biomassa e produção específica da proteína de interesse.

\section{RESULTADOS E DISCUSSÃO}

Dois cultivos de E. coli foram realizados no biorreator convencional, sendo que, em um experimento foi utilizado como indutor IPTG, e o outro, lactose.

Durante o cultivo de E. coli que foi induzido por IPTG, obteve-se um perfil de rápido crescimento, obtendo-se uma concentração final de $27 \mathrm{gMS} / \mathrm{L}$ a partir de Cx inicial de 0,11 gMS/L, após $15 \mathrm{~h}$ de cultivo, como mostra a Figura 1a. A fase de indução teve duração de $4 \mathrm{~h}$, a qual foi iniciada com a adição de um pulso de IPTG em $~ 11 \mathrm{~h}$ de cultivo. Durante toda a fase de indução, a retenção plasmidial no cultivo manteve-se superior a $90 \%$, porém a contagem de UFC mostrou queda de até $92 \%$ no número de células viáveis, não detectada pelo método de massa seca nem pela medida de densidade ótica. O $\mathrm{Y}_{\mathrm{PspA} / \mathrm{X}}$ máximo obtido foi de $199 \mathrm{mgPspA} / \mathrm{gMS}$, sendo que a velocidade de produção de PspA foi constante, como pode ser visto na Figura 1(a).

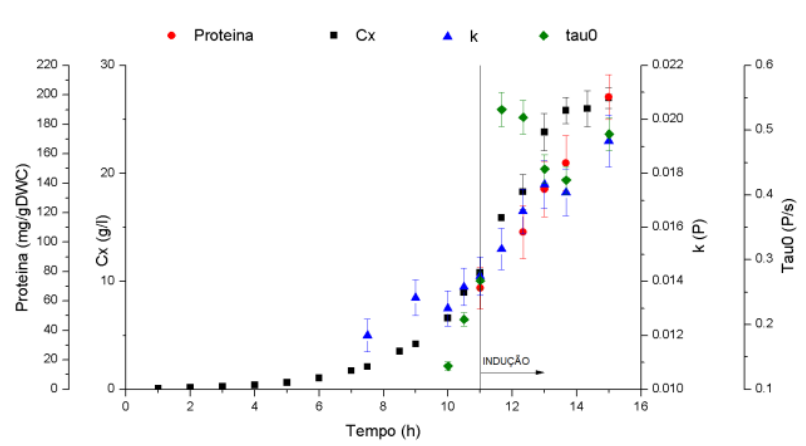

(a)

Figura 1 - Crescimento, reologia e morfologia em cultivo de E. coli BL21(DE3) pET37b+/pspA4Pro induzido por IPTG. (a) Concentrações de biomassa $\left(\mathrm{C}_{\mathrm{x}}\right)$, proteína de interesse (PspA) e parâmetros reológicos (tensão de cisalhamento inicial $-\tau_{0}$ e índice de consistência - $\mathrm{k}$, para $\mathrm{n}=1$ ); (b) distribuição do comprimento celular (indução a partir do tempo 11h). As barras de desvio padrão apresentadas se referem a medidas de $\mathrm{C}_{\mathrm{x}}$ e produção de proteína em triplicata enquanto os parâmetros reológicos apresentam precisão de $\pm 1 \%$ fornecido pelo equipamento. As barras dos boxplots representam os valores de $\pm 1,5 \sigma$.

A Figura 1a também mostra que a reologia do caldo sofreu alterações com o decorrer do tempo. A suspenção comportou-se inicialmente como um fluido newtoniano apresentando uma tendência de crescimento da viscosidade com o aumento da concentração celular até $\mathrm{Cx}$ de 6,6 gMS/L. A partir dessa concentração, o caldo passou a apresentar uma fase de transição para um comportamento binghamiano, que foi rapidamente se intensificando. 
Após a indução, o valor de $\tau_{0}$ atingiu seu valor máximo em $0,532 \mathrm{P} / \mathrm{s}$, sofrendo uma pequena queda nos pontos seguintes, enquanto isso o valor de $\mathrm{k}$ continuou apresentando crescimento em quase todos os pontos, atingindo um valor máximo ao final do cultivo de 1,92 cP. Apesar das mudanças na reologia, Figura $1 \mathrm{~b}$ mostra que a morfologia da $E$. coli não sofreu alterações expressivas durante o cultivo, sendo que a mediana do comprimento das células permaneceu entre 2,6 a 2,8 $\mu \mathrm{m}$, com desvio-padrão entre 1,1 e $1,3 \mu \mathrm{m}$ e número de outliers acima de $3 \sigma$ (indicando a presença de células filamentosas) entre $2,1 \%$ a $2,5 \%$ da população.

No segundo cultivo em biorreator, a indução ocorreu por adição de um pulso de lactose. Esse experimento foi iniciado com um valor de Cx de $0,14 \mathrm{gMS} / \mathrm{L}$, alcançando um valor final de 34,5 gMS/L após 21,5 h, sendo que a fase de indução compreendeu as últimas 12 horas (Figura 2). Durante a fase de indução, a retenção plasmidial no cultivo caiu gradativamente, até atingir o valor mais baixo de $39 \%$ uma hora antes do encerramento do mesmo. A contagem de UFC mostrou novamente uma queda de até $90 \%$ no número de células viáveis, atingindo os valores semelhantes aos observados no cultivo induzido com IPTG. O Y $\mathrm{YspA}_{\mathrm{X}}$ máximo obtido no cultivo foi de $62,6 \mathrm{mgPspA} / \mathrm{gMS}$, o qual foi observado no meio da fase de indução, como pode ser visto na Figura 2(a). A baixa produção de proteína observada nesse experimento pode estar relacionada à formação de metabólitos inibitórios (ácidos acético, lático e fórmico) devido à assimilação da glicose liberada durante a hidrólise da lactose pela $\beta$-galactosidase. $\mathrm{O}$ acúmulo de metabólitos também explicaria a diminuição na concentração de células viáveis e a elevada perda de plasmídeo observadas no segundo cultivo. Análises da concentração desses metabólitos por cromatografia líquida de alta eficiência mostraram acúmulo de 4,30 g/L de acetato, além de 1,39 g/L de lactato e 0,76 g/L de formato, cuja formação se intensificou após a adição do pulso de lactose. O acúmulo desses metabólitos foi desprezível no cultivo induzido por IPTG. Além disso, o prolongado período de indução adotado para a lactose também contribui para uma menor retenção de plasmídeo ao final do cultivo, já que após 4 h de indução a retenção de plasmídeo era similar (90\%) à observada no cultivo com o IPTG.
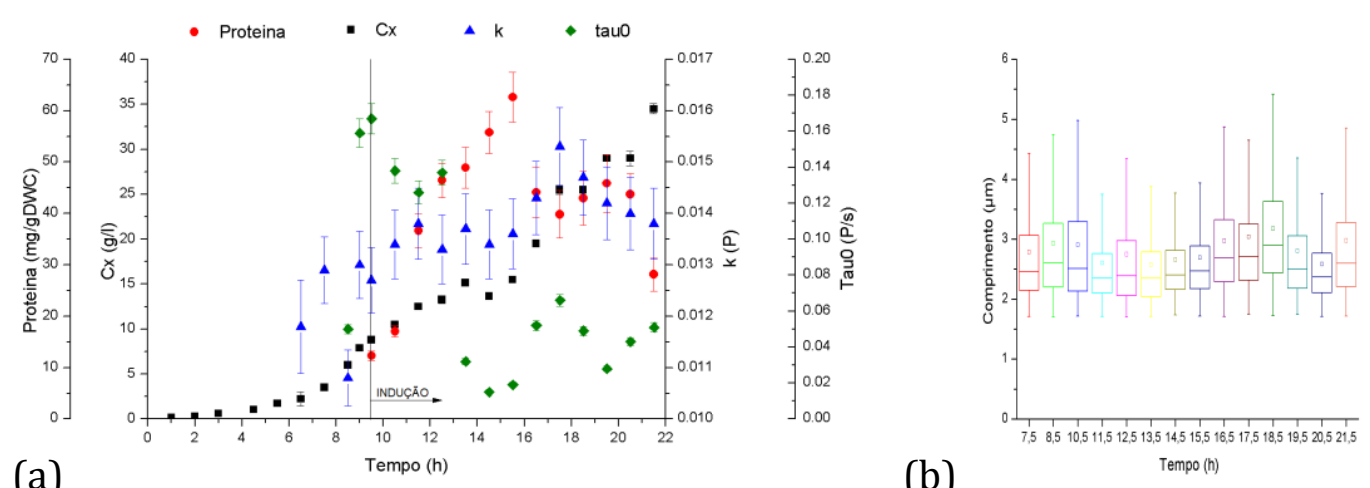

Figura 2 - Crescimento, reologia e morfologia em cultivo de E. coli BL21(DE3) pET37b+/pspA4Pro induzido por lactose. (a) Concentrações de biomassa $\left(\mathrm{C}_{\mathrm{x}}\right)$, proteína de interesse (PspA) e parâmetros reológicos (tensão de cisalhamento inicial $-\tau_{0}$ e índice de consistência - $\mathrm{k}$, para $\mathrm{n}=1$ ); (b) distribuição do comprimento celular (indução a partir do tempo 10,5h). As barras de desvio padrão apresentadas se referem a medidas de $\mathrm{C}_{\mathrm{x}} \mathrm{e}$ produção de proteína em triplicata enquanto os parâmetros reológicos apresentam precisão de $\pm 1 \%$ fornecido pelo equipamento. As dos boxplots representam os valores de $\pm 1,5 \sigma$. 
Em relação ao comportamento reológico (Figura 2a), a suspensão comportou-se como um fluido newtoniano com aumento da viscosidade acompanhando o crescimento celular até atingir Cx de $6 \mathrm{gMS} / \mathrm{L}$. A partir dessa concentração, observou-se novamente a fase de transição para um comportamento binghamiano, conforme ocorreu com o cultivo 1 . No momento da indução, o valor de $\tau_{0}$ atingiu seu valor máximo de $0,167 \mathrm{P} / \mathrm{s}$, decrescendo posteriormente e mantendo-se em torno de $0,08 \mathrm{P} / \mathrm{s}$ durante a maior parte da indução. $\mathrm{O}$ valor máximo atingido por $\mathrm{k}$ foi de $1,53 \mathrm{cP}$, com um perfil de variação aparentemente acompanhando a produção de proteína. O comprimento celular apresentou valores semelhantes aos observados no cultivo anterior durante a fase de crescimento, com alterações consideráveis após a indução. As medianas da distribuição de comprimento variaram entre 2,3 e $2,9 \mu \mathrm{m}$, com desvio padrão entre 0,8 e $1,2 \mu \mathrm{m}$ e número de outliers acima de $3 \sigma$ alcançou máximo de $4,5 \%$.

Os resultados obtidos durante os ensaios foram ainda empregados para avaliar a razão entre DO e Cx (Figura 3) ao longo dos cultivos. Os resultados mostram que durante a fase de crescimento a razão permanece constante e igual a 0,387 (gMS/L/unidade $\mathrm{Abs}_{600 \mathrm{~nm}}$ ), com excelente ajuste do modelo linear aos dados dos dois cultivos realizados (Eq. 2). Porém, depois que o metabolismo celular é direcionado para a produção de proteína, o modelo linear não se mostra mais adequado para representar a variação de Cx em função da DO, que assume perfil exponencial (indução com lactose) ou de saturação (indução com IPTG), conforme mostram as Eqs 3 e 4, respectivamente. As mudanças observadas durante a fase de indução estão associadas ao acúmulo da proteína intracelular, o que explicaria o elevado aumento de Cx em função da DO para valores de DO entre 27 e 50, para o cultivo induzido com lactose. Já para o cultivo induzido com IPTG, a fase de saturação observada para valores de DO superiores a 55 pode estar relacionada com o efeito tóxico causado pelo IPTG.

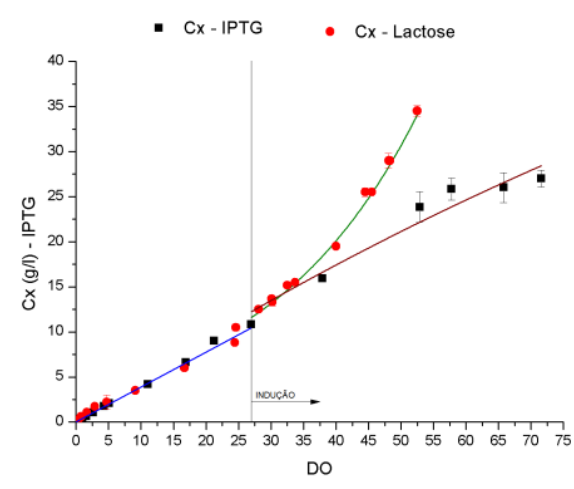

Figura 3 - Concentrações de biomassa $\left(\mathrm{C}_{\mathrm{x}}\right)$ durante os ensaios induzidos por IPTG e lactose em função da densidade ótica. Ajuste da Eq. 2 indicado pela linha azul, ajuste da Eq. 3 indicado pela linha verde e ajuste da Eq. 4 indicado pela linha vermelha. As barras de desvio padrão apresentadas se referem a medidas de $C_{x}$ em triplicata.

$$
\begin{array}{ll}
C x=0,387 \pm 0,008 * D O_{600 \mathrm{~nm}} & \left(\mathrm{r}^{2}=0,996\right) \\
C x=3,7 \pm 0,1 * \exp ^{0,0423 \pm 0,0008 * D O_{600 \mathrm{~nm}}} & \left(\mathrm{r}^{2}=0,997\right) \\
C x=\frac{142 \pm 12 * D O_{600 \mathrm{~nm}}}{286 \pm 29+D O_{600 \mathrm{~nm}}} & \left(\mathrm{r}^{2}=0,935\right)
\end{array}
$$




\section{CONCLUSÕES}

Os resultados mostraram que a produção de produção de proteínas recombinantes por $E$. coli afeta não só o metabolismo das células, mas também apresenta reflexos na reologia do caldo e no perfil da variação da concentração celular com a densidade ótica.

O parâmetro k parece estar ligado à concentração celular já que aparenta acompanhar seu crescimento durante o cultivo. O parâmetro $\tau_{0}$ aparenta estar de alguma forma associado ao estresse sentido pela célula pela produção da proteína. Até a indução ele possui uma tendência de crescimento, atingindo o valor máximo antes ou logo após a adição do indutor, e então passa a cair com o decorrer da fase de indução. A mudança no comportamento reológico do caldo, passando de um fluido newtoniano para um fluido binghamiano pode estar associada não só ao aumento concentração celular, mas também à presença de estresse celular causado pelas próprias condições de cultivo. Da mesma forma, a mudança de perfil da concentração celular em função da densidade ótica de linear para exponencial ou de saturação pode estar associado ao acúmulo de proteína ou ao estresse originado pela produção da proteína recombinante.

Ao contrário do esperado, não foi possível associar as mudanças observadas na reologia a alterações morfológicas. A metodologia empregada para análise da morfologia é altamente suscetível a erro, o qual tentamos minimizar com o aumento do número de indivíduos avaliados por amostra. Porém, além do erro inerente à metodologia, a heterogeneidade da população de células aumenta com o tempo de cultivo, o que também influencia a morfologia, juntamente com os possíveis efeitos do estresse causado pela produção da proteína heteróloga, dificultando a análise isolada deste último.

A incorporação do estudo da reologia e da morfologia aos procedimentos usuais de acompanhamento dos cultivos de $r E$. coli amplia o conhecimento sobre o processo de produção de proteínas recombinantes, além de fornecer subsídios para o desenvolvimento de melhores estratégias de cultivo. Novos ensaios estão em andamento em outras temperaturas para aprofundar os estudos aqui relatados.

Agradecimentos à CAPES e à FAPESP.

\section{REFERÊNCIAS}

ANDRADE, J. V. L; CARRA, M.; SILVA, G. G.; CAMPANI JR., G.; ZANGIROLAMI, T.C. Acompanhamento de mudanças morfológicas em cultivos de Escherichia coli recombinante por análise de imagens utilizando recursos computacionais. Trabalho aceito para publicação nos Anais do X Congresso Brasileiro de Iniciação Científica, Vassouras, RJ, 2013.

BENNETT, C. O., MYERS, J. E. Fenômenos de Transporte: Quantidade de Movimento, Calor e Massa. McGraw-Hill, São Paulo, 1978.

CAMPANI, G. Reator airlift operado em sobrepressão: construção, caracterização da transferência de oxigênio e aplicação em cultivos de Escherichia coli recombinante. 2014. 101 f. Dissertação (Mestrado em Engenharia Química) - Departamento de Engenharia Química, Universidade Federal de São Carlos, São Carlos, 2014. 
HORTA, A. C. L. H. Sistema automático de supervisão e controle de cultivos de alta densidade celular de E. coli recombinante. 2009. 170 f. Tese (Doutorado em Engenharia Química) - Departamento de Engenharia Química, Universidade Federal de São Carlos, São Carlos, 2011.

KOOLAEE, S. M. V., SHOJAOSADATI, S. A., BABAEIPOUR, V., GHAEMI, N., Physiological and morphological changes of recombinant E. coli during over-expression of human interferon- $\gamma$ in HCDC. Iranian Journal of Biotechnology. v 4 (4). Outubro de 2006.

KYLE, S.; JAMES, K. A. R.; MCPHERSON, M. J. Recombinant production of the therapeutic peptide lunasin. Microbial Cell Factories, v. 11, n. 28, p. 1-8, 2012.

LEE, S. Y. Suppression of filamentation in recombinant Escherichia coli by amplified FtsZ activity. Biotechnology letters. v 16 (12). p. 1247-1252. Dezemdro de 1994.

LEE, S. Y., LEE, K. M., CHANG, H. N., STEINBUCHEL, A. Comparison of recombinant Escherichia coli strains for synthesis and accumulation of poly-(3-hydroxybutiric acid) and morphological changes. Biotechnology and bioengeneering. v 44 (11). p. 13371347. Dezembro de 1994.

MANON, Y., FILLAUDEAU, L., ANNE-ARCHARD, D., URIBELARREA, J. L., MOLINA-JOUVE, C., On-line rheology of cell cultures in a bioreactor. 8th World Congress of Chemical Engineering, WCCE8, Montréal, Canada, Agosto 23-27, 2009.

NELSON, D. L., COX, M. M., Lehninger Princípios de Bioquímica. Editora Sarvier, $4^{\text {a }}$ Ed., São Paulo, 2006

SARGO, C.R. Aperfeiçoamento das Condições de Cultivo em Alta Densidade de E. coli recombinante com Glicerol como Fonte de Carbono. Dissertação de Mestrado, PPGEQ/UFSCar, Julho de 2011.

SILVA, G. G., CAMPANI Jr., G., SANTOS, M. P., SARGO, C. R., HORTA, A. C. L., GONÇALVES, V. M., BADINO Jr., A. C., ZANGIROLAMI, T. C. Estudo reológico dos caldos de cultivos de alta densidade celular de E. coli recombinante. In: SIMPÓSIO NACIONAL DE BIOPROCESSOS, 19., 2013, Foz do Iguaçu. Anais... 1 DVD. 